\title{
Low-level environmental lead exposure in childhood and adult intellectual function: a follow-up study
}

Maitreyi Mazumdar ${ }^{1,2^{*}}$, David C Bellinger ${ }^{1,2}$, Matthew Gregas ${ }^{1,3}$, Kathleen Abanilla', Janine Bacic $^{3}$ and Herbert L Needleman ${ }^{4}$

\begin{abstract}
Background: Early life lead exposure might be a risk factor for neurocognitive impairment in adulthood.

Objectives: We sought to assess the relationship between early life environmental lead exposure and intellectual function in adulthood. We also attempted to identify which time period blood-lead concentrations are most predictive of adult outcome.

Methods: We recruited adults in the Boston area who had participated as newborns and young children in a prospective cohort study that examined the relationship between lead exposure and childhood intellectual function. IQ was measured using the Wechsler Abbreviated Scale of Intelligence (WASI). The association between lead concentrations and IQ scores was examined using linear regression.

Results: Forty-three adults participated in neuropsychological testing. Childhood blood-lead concentration (mean of the blood-lead concentrations at ages 4 and 10 years) had the strongest relationship with Full-Scale IQ ( $\beta=$ $-1.89 \pm 0.70, p=0.01)$. Full-scale IQ was also significantly related to blood-lead concentration at age 6 months $(\beta=$ $-1.66 \pm 0.75, p=0.03), 4$ years $(\beta=-0.90 \pm 0.41, p=0.03)$ and 10 years $(\beta=-1.95 \pm 0.80, p=0.02)$. Adjusting for maternal IQ altered the significance of the regression coefficient.

Conclusions: Our study suggests that lead exposure in childhood predicts intellectual functioning in young adulthood. Our results also suggest that school-age lead exposure may represent a period of increased susceptibility. Given the small sample size, however, the potentially confounding effects of maternal IQ cannot be excluded and should be evaluated in a larger study.
\end{abstract}

\section{Background}

Lead is a potent neurotoxicant with demonstrated effects on the brains of children and adults. The weight of evidence supports an association between early life exposure to lead and impaired cognitive function in children [1-3]. Childhood lead exposure might also be a risk factor for neurocognitive impairment in adulthood. Studies have suggested a link between preschool bloodlead concentrations and adult mental retardation $[4,5]$, economic productivity $[6,7]$, delinquency, and violent offences[8,9].

\footnotetext{
* Correspondence: maitreyi.mazumdar@childrens.harvard.edu 'Department of Neurology, Children's Hospital Boston, 300 Longwood Avenue, Boston, MA USA

Full list of author information is available at the end of the article
}

The Boston prospective study was one of several crosssectional and cohort studies that were initiated in the late $1970 \mathrm{~s}$ and early $1980 \mathrm{~s}$ to study the relationship between lead and child development. These studies contributed to the decision by the United States Centers for Disease Control and Prevention to announce a new action level of $10 \mu \mathrm{g} / \mathrm{dL}$ whole blood lead in 1991[10]. Follow-up of this cohort at age 10 years showed a continued association between a child's blood-lead concentration at age two years and cognitive function[11]. This finding was influential in experts concluding that children were especially vulnerable to peak blood-lead concentrations, which typically occur at about two years of age.

The objective of this study was to assess the relationship between early life environmental lead exposure and 
intellectual function in adulthood among a group of young adults who were enrolled in a prospective cohort study as newborns. In addition, we attempted to identify which time period blood-lead concentrations are most predictive of late outcome.

\section{Methods}

\section{Sample}

Between August 1979 and April 1981, a cohort of 249 infants was established among babies born at the Brigham and Women's Hospital in Boston. Umbilical cord blood-lead concentrations were measured, and postnatal blood-lead concentrations and development were assessed at $6,12,18,24$, and 57 months, and again at 10 years[11-13]. Follow-up of this cohort at age 10 years consisted of 148 children ( $87.6 \%$ of those considered eligible; $59.4 \%$ of the original cohort)[13].

In January 2009, subjects were mailed an introductory letter explaining a new study regarding early-life lead exposure and health outcomes in adulthood. Names and last known address were available only for the 148 subjects who participated in the 10-year follow-up. Of these, $89(60 \%)$ were located throughout the United States, and 55 of these (62\%) enrolled in the study, which included completing a questionnaire and donating a blood sample. Forty-three subjects came to Children's Hospital Boston (CHB) for additional neuropsychological testing and constitute the sample for the current study. The sample generally consisted of white, collegeeducated children with college-educated parents (Table 1). Participants were similar to members of the original cohort who did not participate or undergo neuropsychological assessment in terms of demographic factors, measures of socioeconomic status, blood lead history, and IQ scores in early childhood (Table 1).

\section{Neuropsychological Assessment}

A child neurologist (M.M.), trained in the administration of the instrument and unaware of the subject's developmental history and lead concentrations, administered the Wechsler Abbreviated Scale of Intelligence (WASI) to all subjects. The WASI includes four subtests (Vocabulary, Similarities, Block Design and Matrix Reasoning) and provides estimates of Full-Scale IQ, Verbal IQ, and Performance IQ[14]. A senior neuropsychologist (D.C.B.) reviewed $25 \%$ of the WASI protocols to ensure accurate administration and scoring.

\section{Measurement of Potential Confounders}

At the time of enrollment in the current study, subjects completed a questionnaire that gathered demographic information as well as information about education, employment, history of arrests, concurrent medications,
Table 1 Characteristics of the participants at age 28-30 years and comparison with non-participants

\begin{tabular}{|c|c|c|c|}
\hline Characteristic & $\begin{array}{l}\text { Subjects who } \\
\text { participated in IQ } \\
\text { testing }(n=43)\end{array}$ & $\begin{array}{l}\text { Subjects who did } \\
\text { not participate (n } \\
=105)\end{array}$ & $\begin{array}{c}p- \\
\text { value }\end{array}$ \\
\hline \multicolumn{4}{|l|}{ Subjects } \\
\hline $\begin{array}{l}\text { Age at testing } \\
\text { (years) }\end{array}$ & $29.0 \pm 0.5$ & - & \\
\hline $\begin{array}{l}\text { College } \\
\text { graduate }^{a}\end{array}$ & 81.4 & - & \\
\hline Currently smoke $^{a}$ & 23.3 & - & \\
\hline $\begin{array}{l}\text { Alcohol use } \\
\text { more than } 2 \\
\text { drinks/week }^{\text {a }}\end{array}$ & 34.9 & - & \\
\hline $\begin{array}{l}\text { Concussion or } \\
\text { head trauma }^{a}\end{array}$ & 23.8 & - & \\
\hline Ever arrested $^{a}$ & 18.6 & - & \\
\hline Male $^{a}$ & 48.8 & 51.4 & 0.77 \\
\hline White $^{a}$ & 93.0 & 91.2 & 0.70 \\
\hline First born ${ }^{a}$ & 53.5 & 58.7 & 0.59 \\
\hline $\begin{array}{l}\text { Weeks of } \\
\text { gestation }\end{array}$ & $40.0 \pm 1.7$ & $40.0 \pm 2.1$ & 0.96 \\
\hline Birth weight $(\mathrm{kg})$ & $3.4 \pm 0.5$ & $3.4 \pm 0.5$ & 0.76 \\
\hline
\end{tabular}

\begin{tabular}{cccc}
$\begin{array}{c}\text { Blood lead } \\
\text { concentration } \\
(\mu \mathrm{g} / \mathrm{dL})^{\mathrm{b}}\end{array}$ & & & \\
\hline Cord & $6.5 \pm 5.3$ & $7.3 \pm 5.3$ & 0.43 \\
\hline 6 months & $8.0 \pm 5.3$ & $8.4 \pm 7.5$ & 0.74 \\
\hline 12 months & $10.0 \pm 6.7$ & $9.6 \pm 6.5$ & 0.72 \\
\hline 24 months & $7.7 \pm 4.0$ & $8.9 \pm 6.9$ & 0.28 \\
\hline 4 years & $6.7 \pm 3.6$ & $6.3 \pm 4.3$ & 0.64 \\
\hline 10 years & $3.0 \pm 2.7$ & $2.9 \pm 2.3$ & 0.79 \\
\hline $\begin{array}{c}\text { IQ at age } 4 \\
\text { years }\end{array}$ & $117.7 \pm 15.3$ & $114.6 \pm 14.3$ & 0.22 \\
\hline $\begin{array}{c}\text { IQ at age } 10 \\
\text { years }\end{array}$ & $117.7 \pm 15.2$ & $115.3 \pm 13.9$ & 0.36 \\
\hline & & & \\
\hline
\end{tabular}

\begin{tabular}{cccc}
\hline $\begin{array}{c}\text { Subjects' } \\
\text { mothers }\end{array}$ & $30.3 \pm 4.3$ & $30.1 \pm 4.7$ & 0.82 \\
\hline $\begin{array}{c}\text { Age at delivery } \\
\text { (year) }^{\mathrm{b}}\end{array}$ & 60.0 & 59.3 & 0.49 \\
\hline $\begin{array}{c}\text { College } \\
\text { graduate }^{\mathrm{a}}\end{array}$ & $122.8 \pm 19.3$ & $122.4 \pm 17.8$ & 0.90 \\
\hline Maternal IQ $^{\mathrm{b}}$ & $51.4 \pm 4.4$ & $51.0 \pm 3.9$ & 0.60 \\
\hline HOME score & & 26.9 & 0.94 \\
\hline $\begin{array}{c}\text { Tobacco use } \\
\text { during } \\
\text { pregnancy }\end{array}$ & 27.5 & 42.1 & 0.15 \\
\hline $\begin{array}{c}\text { Alcohol use } \\
\text { during } \\
\text { pregnancy }\end{array}$ & 55.0 & & \\
\hline
\end{tabular}

${ }^{a}(\%$ Yes $){ }^{b}$ Mean \pm SD. 
and alcohol and tobacco use. During previous assessments, parents completed several questionnaires about the child's medical history and sociodemographic characteristics, including the Home Observation for Measurement of the Environment (HOME) Inventory[15]. The HOME score is an index reflecting the quality and quantity of emotional and cognitive stimulation in the child's environment. Information about many other potential confounders was available in records from earlier assessments (e.g., maternal IQ, birth weight).

\section{Measures of exposure}

Blood samples were obtained from umbilical cords at birth and directly from subjects using capillary tubes at ages $6,12,18$, and 24 months and via venipuncture at 57 months and 10 years. Blood lead concentrations were measured in duplicate using graphic furnace atomic absorption spectrometry with quality control samples included among sample batches. The details of this method are available in previous reports from this cohort[12,13].

\section{Covariates}

All analyses included prespecified covariates, which consisted of established predictors of children's intellectual outcomes, factors widely used in studies of lead exposure and intelligence, as well as factors in early adulthood that have been shown to affect intellectual outcome. The following variables were used: subject's sex, race, birth weight, birth order, gestational age at delivery, mother's marital status at delivery, highest educational level of mother at delivery, maternal IQ, maternal tobacco use during pregnancy, maternal alcohol use during pregnancy, subject's history of concussion or head trauma, subject's smoking, and subject's use of alcohol.

\section{Statistical Methods}

As predictors of IQ in adulthood, we considered several blood-lead concentrations: umbilical cord blood lead, six months, one year, two years, four years and 10 years, average blood-lead concentration (defined as the mean blood-lead concentration between birth and 10 years), maximum blood-lead concentration (defined as the highest blood-lead concentration measured from birth to 10 years), average late childhood blood-lead concentration (defined as the mean of four year and 10 year blood-lead concentrations), and early childhood bloodlead concentration (defined as the mean blood-lead concentration from six months to two years and as the mean blood-lead concentration from birth to two years). Spearman correlations were computed for lead and covariates and for IQ and covariates. We fit separate linear regression models with each lead measure as the predictor and IQ as the response. We further attempted to determine the pattern of exposure's influence on IQ by specifying a model that contained terms for the ratio of 10 year (and subsequently, four year) blood-lead concentration to the two year blood-lead concentration in addition to the average late childhood blood concentration.

The lead-IQ models describe only the marginal relationship between blood-lead concentrations and IQ and do not control for the effect of confounders. The small sample size prevented us from fitting a multiple regression model with all the variables plus lead concentrations as predictors. We did, however, want to determine which of these covariates affected the relationship between blood-lead concentrations and IQ. Thus we added each covariate one at a time to the model with lead as the sole predictor. If the significance of the regression coefficient for the blood lead measure changed from below 0.05 to above 0.05 as a result of adding the candidate covariate to the model, we labeled the term to be a possible confounder that would have to be accounted for in a larger study. All model assumptions were validated with residual plots.

\section{Results}

\section{Blood lead concentration}

The mean blood lead concentration was lowest at the age of 10 years $(3.0 \mu \mathrm{g} / \mathrm{dL})$, and was maximal at age two years $(10.0 \mu \mathrm{g} / \mathrm{dL})$ (Table 1$)$. The median concentrations followed a similar pattern (Figure 1). The highest concentrations were seen in infancy and early childhood, possibly reflecting greater lead intake through hand-tomouth activity and higher exposures in that era. Only five subjects had blood-lead concentrations at each measuring point that were below $10.0 \mu \mathrm{g} / \mathrm{dL}$, and so separate analyses for subjects whose lead exposures were below $10.0 \mu \mathrm{g} / \mathrm{dL}$ were not possible. In general, however, subjects in our study had lower lead exposures than similar cohorts of the time period

\section{Intelligence test results}

The mean Full-Scale IQ in our sample was approximately 122 at age 29 years. Adult IQs were strongly correlated with IQ scores at the ages of 57 months and 10 years $(\mathrm{r}=0.68, \mathrm{p}<0.001$ and $\mathrm{r}=0.67, \mathrm{p}<0.001$ respectively). IQ scores in early adulthood were also strongly correlated with maternal IQ $(\mathrm{r}=0.63, \mathrm{p}<0.001)$. The bivariate associations between the subject's IQ, blood lead concentration and other covariates were in the expected direction.

\section{Blood lead concentrations and IQ}

We examined the relationship between Full-Scale IQ and eleven blood lead measures. Full-Scale IQ was 


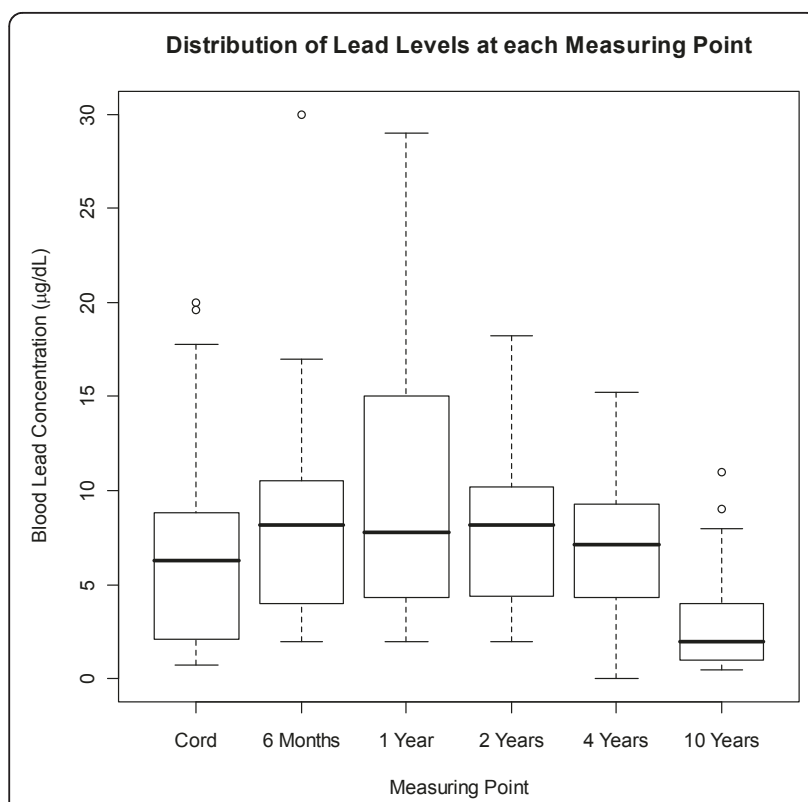

Figure 1 Distribution of lead levels at each measuring point. In each box plot, the median value is indicated by the center horizontal line and the $25^{\text {th }}$ and $75^{\text {th }}$ percentiles are indicated by the lower and upper horizontal lines, respectively. The vertical lines represent 1.5 times the interquartile range, and circles represent outliers (i.e. values that are more than 1.5 times the interquartile range). To convert values for lead to micromoles per liter, multiply by 0.0483 .

significantly related to blood-lead concentration at 6 months $(\mathrm{p}=0.03)$, four years $(\mathrm{p}=0.04), 10$ years $(\mathrm{p}=$ $0.020)$, average blood-lead concentration $(p=0.03)$, and average late childhood blood-lead concentration $(\mathrm{p}=$ 0.01). Although all these measures are related to FullScale IQ, average late childhood blood lead (defined as the mean of blood-lead concentrations at age four years and age 10 years) had the strongest relationship with Full-Scale IQ as measured by regression coefficient and $R^{2}$. Average late childhood blood lead and average blood lead were used in all subsequent analyses as the primary lead exposure indices because both of these measures were related to Full-Scale IQ and also took into account the lead concentrations at each age that were also shown to be related to Full-Scale IQ.

Similar findings were seen in analyses of Performance and Verbal IQ (Table 2). Performance IQ was significantly related to blood-lead concentration at 6 months $(p=0.03), 4$ years $(p=0.02)$ and average blood-lead concentration $(p=0.02)$. Verbal IQ was significantly related to blood-lead concentration at 10 years $(\mathrm{p}=0.001)$. As with Full-Scale IQ, the blood-lead concentrations in childhood had stronger associations with Performance and Verbal IQ than blood-lead concentrations at earlier ages. For subsequent analyses, we decided to focus on Full-Scale IQ to facilitate comparison with other studies.
The relationship between blood lead indices and FullScale IQ was determined to be linear. Previous literature suggests that the logarithm of lead concentration is a better linear predictor of IQ than lead on the natural scale[3,16,17]. In our data set we found that taking the logarithm did not improve the fit so we chose to express lead on its measured scale. Furthermore, the model with logarithm of lead did not improve model fit as determined by the Akaike Information Criterion (AIC) and the model residuals.

We attempted to test whether the pattern of exposure is an important modifier of lead exposure following the methods developed by Hornung et al[18]. We added the ratio of 10 year (and subsequently four year) blood-lead concentration over two year blood-lead concentration to the model with average late childhood blood-lead concentration. The parameters associated with the ratio terms were not significant and therefore were not included in further testing. There are several variables that may affect the relationship between Full-Scale IQ and blood-lead concentrations. For example, inclusion of maternal IQ in the model affected the relationship between Full-Scale IQ and average childhood blood-lead concentration (Table 3). When maternal IQ was added to the model the coefficient for the childhood blood lead index was reduced from $-1.89(-3.30,-0.47,95 \% \mathrm{CI})$ to $-1.11(-2.29,0.06,95 \% \mathrm{CI})$ and the significance of the regression coefficient changed.

\section{Discussion}

Three findings from this study support the hypothesis that there are long-term consequences of environmental lead exposure among children in the United States. Of primary importance is that intellectual functioning in adulthood, as measured by Full-Scale IQ, is inversely associated with blood lead concentrations in childhood. This suggests that the adverse effects of early-life lead exposure are persistent. We recruited adults aged 28 to 30 years who, as newborns, participated in a prospective study of lead and neurodevelopment. This length of follow-up is well past the time horizon of most epidemiological studies. The findings of this study are consistent with other investigations that have found that early exposure to lead is associated with long-term and apparently irreversible effects on behavioral, cognitive, and neuroradiological endpoints in adults[8,19-23].

The second, related finding is that the association between IQ and blood-lead concentration was seen in a cohort with generally lower body lead burden than other cohorts assembled during that era, and lower blood lead concentrations than the current level of concern set by the CDC and WHO[24,25]. This finding is consistent with several other cohort studies that examined the relationship of blood lead concentrations and 
Table 2 Unadjusted Changes in IQ for Each Increase in the Blood Lead Concentration of 1 microgram per Deciliter

\begin{tabular}{|c|c|c|c|c|c|c|c|c|c|c|}
\hline \multirow{2}{*}{$\begin{array}{c}\text { Type of Blood Lead } \\
\text { Measurement }\end{array}$} & \multirow[b]{2}{*}{$n$} & \multicolumn{3}{|c|}{ Full-Scale IQ } & \multicolumn{3}{|c|}{ Verbal IQ } & \multicolumn{3}{|c|}{ Performance IQ } \\
\hline & & $\beta \pm S E$ & $p$ & $\mathrm{R}^{2}$ & $\beta \pm S E$ & $p$ & $\mathrm{R}^{2}$ & $\beta \pm S E$ & $p$ & $\mathrm{R}^{2}$ \\
\hline $\begin{array}{l}\text { Average late childhood } \\
\text { (mean of } 4 \mathrm{yr} \text { and } 10 \mathrm{yr} \text { ) }\end{array}$ & 42 & $\begin{array}{l}-1.89 \pm 0.70 \\
(-3.30,-0.47)\end{array}$ & 0.01 & 0.154 & $\begin{array}{l}-1.98 \pm 0.76 \\
(-2.68,0.01)\end{array}$ & 0.12 & 0.145 & $\begin{array}{l}-1.33 \pm 0.66 \\
(-2.68,0.01)\end{array}$ & 0.05 & 0.091 \\
\hline $\begin{array}{c}\text { Average } \\
\text { (mean of all available) }\end{array}$ & 43 & $\begin{array}{l}-1.66 \pm 0.75 \\
(-3.18,-0.14)\end{array}$ & 0.03 & 0.106 & $\begin{array}{l}-1.22 \pm 0.83 \\
(-3.06,-0.30)\end{array}$ & 0.15 & 0.050 & $\begin{array}{l}-1.68 \pm 0.68 \\
(-3.06,-0.30)\end{array}$ & 0.02 & 0.129 \\
\hline 6 months & 39 & $\begin{array}{l}-0.90 \pm 0.41 \\
(-1.73,-0.77)\end{array}$ & 0.03 & 0.117 & $\begin{array}{l}-0.80 \pm 0.45 \\
(-1.71,0.11)\end{array}$ & 0.08 & 0.080 & $\begin{array}{l}-0.81 \pm 0.37 \\
(-1.57,-0.06)\end{array}$ & 0.03 & 0.115 \\
\hline 4 years & 40 & $\begin{array}{l}-1.26 \pm 0.58 \\
(-2.43,-0.09) \\
\end{array}$ & 0.04 & 0.110 & $\begin{array}{l}-0.96 \pm 0.64 \\
(-2.27,0.35) \\
\end{array}$ & 0.14 & 0.055 & $\begin{array}{r}-1.25 \pm 0.51 \\
(-2.29,0.22) \\
\end{array}$ & 0.02 & 0.136 \\
\hline 10 years & 37 & $\begin{array}{l}-1.95 \pm 0.80 \\
(-3.56,-0.33)\end{array}$ & 0.02 & 0.145 & $\begin{array}{l}-2.84 \pm 0.81 \\
(-4.49,1.19)\end{array}$ & 0.001 & 0.258 & $\begin{array}{l}-0.52 \pm 0.72 \\
(-1.98,0.99)\end{array}$ & 0.48 & 0.520 \\
\hline
\end{tabular}

cognitive development (IQ or psychometric intelligence) in children. For example, in an analysis of the Rochester Longitudinal study [17], the change in IQ per given change in lead concentration was greater among children whose maximal blood lead concentration remained below $10 \mu \mathrm{g} / \mathrm{dL}$ than it was among those children with a maximal blood lead concentration greater than $10 \mu \mathrm{g} /$ dL. In a subsequent follow-up assessment of this cohort, children with mean blood lead concentrations between 5.0 and $9.9 \mu \mathrm{g} / \mathrm{dL}$ scored 4.9 IQ points lower than children with blood-lead concentrations below $5.0 \mu \mathrm{g} / \mathrm{dL}$ [26].

The third notable finding from our study is that lead concentrations during the school age years are related to IQ in adulthood, and may represent a time period of greater susceptibility to environmental lead exposure, or more stable blood lead body burden. Previous studies using this same cohort of children showed that children's IQ scores and their scores on other neurocognitive tests were much more strongly associated with blood-lead concentrations at age 24 months than with blood-lead concentrations at other ages [13]. This observation supported the hypothesis that this time period represented a window of special vulnerability to lead. More recent studies, however, suggest that lead exposure at school age may be more strongly related to performance on cognitive testing[27,28]. A pooled analysis of seven cohorts [3] found that concurrent lead concentrations have the strongest relationship to IQ, but that early childhood average, lifetime childhood average and

Table 3 Unadjusted model and models adjusted for important covariates

\begin{tabular}{|c|c|c|c|c|c|}
\hline Covariate & $\begin{array}{l}\text { N (Undaj. } \\
\text { Model) }\end{array}$ & $\begin{array}{l}\mathrm{N} \\
\text { (Adj. } \\
\text { Model) }\end{array}$ & $\begin{array}{l}\text { Adjusted estimate } \\
\text { for lead } \\
{[\beta(95 \% \mathrm{Cl})]}\end{array}$ & $\begin{array}{c}\text { Spearman Correlation } \\
\text { between lead level and } \\
\text { covariate }\end{array}$ & $\begin{array}{c}\text { Spearman Correlation } \\
\text { between Total IQ and } \\
\text { covariate }\end{array}$ \\
\hline None & 42 & - & $-1.89(-3.30,-0.47)$ & - & - \\
\hline Gender & 42 & 42 & $-1.88(-3.31,-0.45)$ & 0.02 & 0.01 \\
\hline Birth Weight & 42 & 42 & $-1.46(-2.69,-0.24)$ & -0.13 & 0.56 \\
\hline Birth Order (first born/not first born) & 42 & 42 & $-1.74(-3.18,-0.30)$ & 0.17 & -0.21 \\
\hline Gestational age & 42 & 42 & $-1.88(-3.25,-0.52)$ & 0.03 & 0.30 \\
\hline $\begin{array}{l}\text { Mother's marital status (married/not } \\
\text { married) }\end{array}$ & 42 & 39 & $-2.00(-3.57,-0.43)$ & 0.20 & -0.28 \\
\hline $\begin{array}{l}\text { Mother's education (college/no } \\
\text { college) }\end{array}$ & 42 & 39 & $-1.89(-3.33,-0.45)$ & -0.25 & 0.39 \\
\hline Maternal IQ & 42 & 42 & $-1.11(-2.29,0.06)$ & -0.24 & 0.67 \\
\hline Race (white/nonwhite) & 42 & 42 & $-1.76(-3.35,-0.17)$ & -0.37 & 0.29 \\
\hline $\begin{array}{l}\text { Maternal Smoking During } \\
\text { pregnancy }(\mathrm{y} / \mathrm{n})\end{array}$ & 42 & 39 & $-1.62(-3.04,-0.21)$ & 0.29 & -0.51 \\
\hline $\begin{array}{l}\text { Maternal Alcohol Use During } \\
\text { pregnancy }(y / n)\end{array}$ & 42 & 39 & $-2.28(-3.88,-0.68)$ & 0.09 & -0.03 \\
\hline HOME score (mean of all collected) & 42 & 42 & $-1.45(-2.89,-0.01)$ & -0.25 & 0.38 \\
\hline Concussion $(y / n)$ & 42 & 41 & $-1.84(-3.32,-0.36)$ & -0.19 & -0.08 \\
\hline Subject current smoking $(\mathrm{y} / \mathrm{n})$ & 42 & 42 & $-1.56(-2.97,-0.14)$ & 0.24 & -0.38 \\
\hline
\end{tabular}


peak blood-lead concentrations also had an inverse relationship to IQ in late childhood. Our study uses both average lifetime lead exposure and childhood lead exposure (average of lead concentrations at age four and 10 years), with the stronger association found in the measure using blood-lead concentrations at older ages.

Our study has a number of important limitations, the most important of which is its small sample size. The small numbers of subjects limited our ability to perform multivariate analysis and evaluate the effect of important potential confounders or interactions. We were able to evaluate a number of potentially confounding variables, including the HOME score, maternal education and maternal IQ, on which information was collected prospectively. Adjusting for maternal IQ altered the significance of the regression coefficient for blood-lead concentration. With this small sample size, however, it is difficult to state that maternal IQ explains all the variability in subjects' IQ, that is, that maternal IQ confounds the effect seen in the unadjusted model. An alternative explanation is that maternal IQ is collinear with lead exposure (mothers with higher IQs took active steps to limit lead exposure, or lived in housing with less lead exposure) and therefore should not be used in models. In any case, our finding that average late childhood blood-lead concentrations are associated with IQ in adulthood should be replicated in other cohorts with larger sample sizes.

\section{Conclusions}

Our study suggests that lead exposure in childhood predicts intellectual functioning in young adulthood. The results also suggest that school-age lead exposure may represent a period of increased susceptibility. Given the small sample size, however, the potentially confounding effects of maternal IQ cannot be excluded and should be evaluated in a larger study.

\section{Abbreviations \\ HOME: Home Observation for Measurement of the Environment; IQ: intelligence quotient; WASI: Wechsler Abbreviated Scale of Intelligence.}

\section{Acknowledgements \\ Dr. Mazumdar was supported by T32 MH073122 and by K23 ES017437. Additional support was provided by Pilot Project funding from the $\mathrm{HSPH}$ - NIEHS Center for Environmental Health (ES000002) and the Harvard Clinical and Translational Science Center (NIH Award UL1 RR024758 and financial contributions from Harvard University and its affiliated academic health care centers). The content is solely the responsibility of the authors and does not necessarily represent the official views of Harvard Catalyst, Harvard University and its affiliated academic health care centers, the National Center for Research Resources, or the National Institutes of Health.}

\section{Author details}

'Department of Neurology, Children's Hospital Boston, 300 Longwood Avenue, Boston, MA USA. ²Department of Environmental Health, Harvard School of Public Health, 665 Huntington Avenue, Boston, MA USA. ${ }^{3}$ Clinical Research Program, Children's Hospital Boston, 300 Longwood Avenue,
Boston, MA USA. ${ }^{4}$ University of Pittsburgh School of Medicine, Pittsburgh, PA USA.

\section{Authors' contributions}

The study was designed by MM, DCB and HLN. MM and DCB performed the IQ assessments. KA, MM, MG and JB performed the statistical analysis. The first draft of the manuscript was written by MM and comments and changes were made by KA, MG, JB, and DCB. All authors have approved the final manuscript.

\section{Competing interests}

The authors declare that they have no competing interests.

Received: 20 December 2010 Accepted: 30 March 2011 Published: 30 March 2011

\section{References}

1. Bellinger DC: Lead. Pediatrics 2004, 113:1016-1022.

2. Needleman H: Lead poisoning. Annu Rev Med 2004, 55:209-222.

3. Lanphear BP, Hornung R, Khoury J, Yolton K, Baghurst P, Bellinger DC, Canfield RL, Dietrich KN, Bornschein R, Greene T, Rothenberg SJ, Needleman HL, Schnaas L, Wasserman G, Graziano J, Roberts R: Low-level environmental lead exposure and children's intellectual function: an international pooled analysis. Environ Health Perspect 2005, 113:894-899.

4. Carpenter DO, Nevin R: Environmental causes of violence. Physiol Behav 2010, 99:260-268.

5. Nevin R: Trends in preschool lead exposure, mental retardation, and scholastic achievement: association or causation? Environ Res 2009, 109:301-310

6. Grosse SD, Matte TD, Schwartz J, Jackson RJ: Economic gains resulting from the reduction in children's exposure to lead in the United States. Environ Health Perspect 2002, 110:563-569.

7. Schwartz J: Societal benefits of reducing lead exposure. Environ Res 1994, 66:105-124.

8. Wright JP, Dietrich KN, Ris MD, Hornung RW, Wessel SD, Lanphear BP, Ho M, Rae MN: Association of prenatal and childhood blood lead concentrations with criminal arrests in early adulthood. PLoS Med 2008, 5:e101.

9. Needleman HL, McFarland C, Ness RB, Fienberg SE, Tobin MJ: Bone lead levels in adjudicated delinquents. A case control study. Neurotoxicol Teratol 2002, 24:711-717.

10. Preventing Lead Poisoning in Young Children. Atlanta: US Centers for Disease Control; 1991.

11. Bellinger D, Sloman J, Leviton A, Rabinowitz M, Needleman $H L$, Waternaux C: Low-level lead exposure and children's cognitive function in the preschool years. Pediatrics 1991, 87:219-227.

12. Bellinger $D$, Leviton $A$, Waternaux $C$, Needleman $H$, Rabinowitz $M$ : Longitudinal analyses of prenatal and postnatal lead exposure and early cognitive development. N Engl J Med 1987, 316:1037-1043.

13. Bellinger DC, Stiles KM, Needleman HL: Low-level lead exposure, intelligence and academic achievement: a long-term follow-up study. Pediatrics 1992, 90:855-861.

14. Wechsler D: Wechsler Abbreviated Scales of Intelligence San Antonio, TX: Psychological Corp; 1999.

15. Caldwell B, Bradley R: Home Observation for Measurement of the Environment Little Rock, AR: University of Arkansas at Little Rock; 1984.

16. Schwartz J: Low-level lead exposure and children's IQ: a meta-analysis and search for a threshold. Environ Res 1994, 65:42-55.

17. Canfield RL, Henderson CR Jr, Cory-Slechta DA, Cox C, Jusko TA Lanphear BP: Intellectual impairment in children with blood lead concentrations below 10 microg per deciliter. N Engl J Med 2003, 348:1517-1526.

18. Hornung RW, Lanphear BP, Dietrich KN: Age of greatest susceptibility to childhood lead exposure: a new statistical approach. Environ Health Perspect 2009, 117:1309-1312.

19. Yuan W, Holland SK, Cecil KM, Dietrich KN, Wessel SD, Altaye M, Hornung RW, Ris MD, Egelhoff JC, Lanphear BP: The impact of early childhood lead exposure on brain organization: a functional magnetic resonance imaging study of language function. Pediatrics 2006 118:971-977 
20. Cecil KM, Brubaker CJ, Adler CM, Dietrich KN, Altaye M, Egelhoff JC, Wessel S, Elangovan I, Hornung R, Jarvis K, Lanphear BP: Decreased brain volume in adults with childhood lead exposure. PLoS Med 2008, 5:e112.

21. Cecil KM, Dietrich KN, Altaye M, Egelhoff JC, Lindquist DM, Brubaker CJ, Lanphear BP: Proton Magnetic Resonance Spectroscopy in Adults with Childhood Lead Exposure. Environ Health Perspect 2010.

22. Brubaker CJ, Dietrich KN, Lanphear BP, Cecil KM: The influence of age of lead exposure on adult gray matter volume. Neurotoxicology 2010 31:259-266.

23. Brubaker CJ, Schmithorst VJ, Haynes EN, Dietrich KN, Egelhoff JC, Lindquist DM, Lanphear BP, Cecil KM: Altered myelination and axonal integrity in adults with childhood lead exposure: a diffusion tensor imaging study. Neurotoxicology 2009, 30:867-875.

24. Preventing lead poisoning in young children: A Statement by the Centers for Disease Control and Prevention, August 2005. Atlanta, CDC; 2005.

25. International Programme on Chemical Safety. Inoganic lead. Environmental health criteria. 165. Geneva, World Health Organization; 1995.

26. Jusko TA, Henderson CR, Lanphear BP, Cory-Slechta DA, Parsons PJ Canfield RL: Blood lead concentrations $<10 \mathrm{microg} / \mathrm{dL}$ and child intelligence at 6 years of age. Environ Health Perspect 2008, 116:243-248.

27. Chen A, Dietrich KN, Ware JH, Radcliffe J, Rogan WJ: IQ and blood lead from 2 to 7 years of age: are the effects in older children the residual of high blood lead concentrations in 2-year-olds? Environ Health Perspect 2005, 113:597-601.

28. Wasserman GA, Liu X, Popovac D, Factor-Litvak P, Kline J, Waternaux C, Lolacono N, Graziano JH: The Yugoslavia Prospective Lead Study: contributions of prenatal and postnatal lead exposure to early intelligence. Neurotoxicol Teratol 2000, 22:811-818.

doi:10.1186/1476-069X-10-24

Cite this article as: Mazumdar et al.: Low-level environmental lead exposure in childhood and adult intellectual function: a follow-up study. Environmental Health 2011 10:24.

\section{Submit your next manuscript to BioMed Central and take full advantage of:}

- Convenient online submission

- Thorough peer review

- No space constraints or color figure charges

- Immediate publication on acceptance

- Inclusion in PubMed, CAS, Scopus and Google Scholar

- Research which is freely available for redistribution

Submit your manuscript at www.biomedcentral.com/submit 